\title{
Después del euro: soberanía nacional y hospitalidad europea ${ }^{1}$
}

\author{
After the Euro: \\ National Sovereignty and European Hospitality
}

\author{
Davide TARIZZO \\ Università degli Studi di Salerno \\ davide.tarizzo@gmail.com
}

\section{Resumen}

Este artículo argumenta a favor de una solución original a la actual crisis política del proceso de integración europea. La idea subyacente es la de un doble espacio político: el espacio de la soberanía y el espacio de la hospitalidad. Mientras el primero es visto tradicionalmente como el espacio político de los Estados-nación europeos, el segundo podría ser concebido como el espacio político de una nueva Unión Europea, donde ambos, UE y Estados nacionales no-UE podrían encontrar su lugar. Esto implica que renunciemos a la categoría de ciudadano europeo y en su lugar adoptemos la nueva categoría política de huésped europeo. Una solución como ésta ha de ser tomada en seria consideración si la crisis de la eurozona finalmente pone en cuestión la unión monetaria europea y socava el proyecto de los "Estados Unidos de Europa".

Palabras clave: crisis de la Eurozona, integración política europea, soberanía, hospitalidad, flujos migratorios.

\begin{abstract}
This paper argues for an original solution of the current political crisis affecting the process of European integration. The underlying idea is that of a double political space: the space of sovereignty and the space of hospitality. While the former is traditionally seen as the political space of the European Nation-States, the latter might be conceived as the political space of a new European Union, where both EU and non-Eu nationals could find their place. This implies that we renounce the category of European citizen and adopt the new political category of European guest
\end{abstract}

\footnotetext{
${ }^{1}$ Traducción Jorge Álvarez Yágüez.
} 
instead. Such a solution should be taken into serious consideration if the eurozone crisis will eventually call into question the European currency union and undermine the project of the "United States of Europe".

Keywords: Eurozone crisis, European political integration, sovereignty, hospitality, migratory fluxes.

Demokratie und Nationalismus, das ist eines Ursprungs, das ist ein und dasselbe. Und schuldig [...] an dem heutigen Zustand Europas, an seiner Anarchie, an dem Kampf aller gegen alle, an diesem Kriege ist die nationalistische Demokratie. Das nationales Prinzip ist das atomistische, das anarchistische, das anti-europäische, das reaktionäre Prinzip. Die Demokratie ist reaktionär, denn sie ist nationalistisch und ohne jedes europäische Gewissen².

El fracaso ya sentenciado del proyecto constitucional europeo y el por ahora solo posible pero cercano de la unión monetaria plantean con urgencia el problema de una eventual reconfiguración de los ordenamientos de la Unión Europea. Si la moneda única se derrumbase finalmente bajo los golpes de la especulación financiera y de las violentas tensiones sociales que son siempre su dramático corolario histórico, el proyecto de inyectar en la UE y en sus órganos institucionales dosis masivas de soberanía (por ejemplo: fiscal) a expensas de la soberanía nacional conocería una traumática fase de detención. En esta perspectiva, infausta cuanto se quiera pero no implausible, es oportuno preguntarse si el desbancamiento de la soberanía estatal existente con miras a la rápida creación de una entidad política supranacional y soberana como los Estados Unidos de Europa sea el único camino practicable hacia la integración política del continente. ¿Debemos obligatoriamente pensar en una Europa política con el léxico y la gramática de la soberanía? Sí, indudablemente, si pensamos en una Europa política fuerte. No, si pensamos en una Europa política débil. Sí, si creemos que la soberanía es el horizonte insuperable de nuestra teoría y práctica política. No, si intentamos imaginar soluciones diversas que diseñen un recorrido de transición hacia una futura, y no próxima, Europa soberana. Ilustraré aquí con breves trazos cómo se podría dar cuerpo a esta segunda alternativa sin separarse de la realidad sino, por el contrario, tratando de aferrar y nombrar lo existente. La finalidad de esta intervención no es naturalmente la de presentar la respuesta a todos los problemas, una respuesta ya empaquetada y dispuesta para el uso, sino la de abrir un debate público e iniciar un programa político de investigación. Como dijera el abate Sieyès

\footnotetext{
${ }^{2}$ T. Mann, Betrachtungen eines Unpolitischen, Frankfurt a/M, S. Fischer Verlag, 1974, pp. 206-207. "Democracia y nacionalismo tienen el mismo origen, son una sola y la misma cosa. Y culpable [...] de la condición actual de Europa, de su anarquía, de la lucha de todos contra todos, culpable de esta guerra es la democracia nacionalista. El principio nacional es atomístico, anárquico, anti-europeo, reaccionario. La democracia es reaccionaria, puesto que es nacionalista y sin conciencia europea alguna".
} 
al culmen de una crisis de gravedad pareja a la que estamos atravesando en Europa: "Los charlatanes sin ideas, y hay muchos, repiten de continuo frases piadosas como las que llaman la atención sobre la importancia de la práctica y la inutilidad, o el peligro, de la teoría. No tengo más que una respuesta que dar: ¿Imagináis por acaso una lista de cosas para hacer, sabias, útiles, excelentes; y no creéis que exista a nivel teórico una secuencia de ideas o verdad correspondiente punto por punto a vuestra lista práctica? Si no habéis perdido completamente la razón, ésta le sigue o, mejor, le precede"s.

La geometría política actual de la Unión Europea la convierte en un espacio de libre circulación de bienes y servicios, capitales y personas. A este primer pilar de la UE que es el mercado común, reforzado en el curso de los años con la unión monetaria, se añaden otros dos: política exterior y de seguridad común; cooperación judicial y de policía en materia penal. Sabemos cuánto ha estado descoordinada y sin influencia hasta ahora la política exterior de la UE, neutralizada por el juego de los intereses nacionales. También en este caso, el peso de las distintas soberanías estatales parece oponerse a todo diseño federalista. Queda así una diferencia profunda y aparentemente incolmable entre espacios políticos heterogéneos: el espacio de la soberanía, diseñado por las fronteras administrativas de los Estados europeos, y un espacio mayor, el de la Unión Europea, comprensivo de los espacios nacionales soberanos, pero privado el mismo de claros y distintos atributos de soberanía. Dada una tal diferencia, y la reluctancia de los pueblos europeos a ver disuelta su propia soberanía en el diseño de una Europa federal, hay que preguntarse qué tipo de codificación jurídico-política de la UE podría garantizar en este punto alguna forma de integración. ¿Cómo podría hacerse convivir los espacios de la soberanía nacional con un espacio político europeo que no vaya en detrimento ni amenace, al menos por el momento, la pretensión de soberanía de los distintos Estados? La historia no ofrece ejemplos que puedan servir de guía.

Nunca una comunidad humana de identidad política rocosa y resistente a la intemperie como son las naciones ha tratado de iniciar la vía de una pacífica integración política. Nunca pueblos habituados a ejercer su soberanía democrática en el marco de mitologemas nacionales que están en la base de sus mismas Constituciones han osado acometer un paso tan audaz. Y nunca, por lo demás, en los Estados europeos, de la Segunda guerra mundial a hoy, se ha hecho sentir de una manera tan aguda el peligro de una vertiginosa regresión antidemocrática: en ausencia de un "pueblo europeo", en ausencia de un nuevo pueblo soberano y supranacional del que por ahora no se entrevé siquiera la sombra en el horizonte, el proceso actual de integración política en Europa corre, en efecto, el riesgo de anular, volens nolens, el principio cardinal de la soberanía popular sobre el que se fundan todos los ordenamientos

\footnotetext{
${ }^{3}$ E.-J. Sieyès, “Quést-ce que le Tiers État?”, en Écrits politiques, Bruxelles, Editions Archives Contemporaines, 1994, p. 186.
} 
políticos modernos. Desde este punto de vista - conviene tomar nota- , si la crítica de los nacionalismos europeos aparece de muchas maneras comprensible y justificada, tiende también a olvidarse demasiado rápido que en la raíz de las democracias europeas, y de sus relativas Constituciones, están siempre los pueblos-nación. Así como tiende a olvidarse con igual ligereza que sin estos pueblos-nación dotados de suficiente homogeneidad política la democracia en Europa no habría sido ni sería aun concebible, practicable.

Entonces, de nuevo: ¿Cómo relanzar el proyecto de una Europa política? ¿Cómo hacerlo respetando plenamente la inspiración originaria? ¿Cómo construir una paz sólida y duradera sobre el continente salvaguardando al mismo tiempo las raíces democráticas de la vida política en Europa? Si la historia no ofrece ejemplos a los que atenerse, no queda sino la invención política. Una invención que, al explorar lo nuevo, no podrá librarse en el vacío sino que deberá partir de lo que hay, deberá salir al encuentro de lo existente trazando un punto de tangencia entre pasado y futuro para tornarlo, finalmente, un auténtico presente.

Lo que hay: una doble dimensionalidad del espacio político. Todo europeo vive hoy simultáneamente en dos espacios políticos heterogéneos, su Estado y la UE, así como pertenece a dos comunidades políticas, su pueblo-nación y un otro pueblo, un pueblo que aún no es, el pueblo europeo, un pueblo que hasta ahora -evidentemente- no ha sido mencionado de manera apropiada. Esta doble pertenencia a un doble espacio político no puede ser reabsorbida en una única pertenencia a un único espacio político. Esto es lo que la historia europea de los últimos veinte años habrá demostrado si la crisis de la deuda destroza definitivamente la unión monetaria. Que la Unión Europea, al menos por el momento, no puede englobar y reemplazar a los Estados soberanos. Que el proyecto federalista, al menos por ahora, no puede funcionar. Que, por eso, se trata de mantener separados los dos espacios políticos y las dos pertenencias. Los Estados son soberanos. Europa, por su lado ¿qué es? ¿qué puede ser? Podremos llamarla, por cómo se presenta hoy a la mirada de quien la contempla con ojos políticos, un espacio de hospitalidad.

En efecto, cada uno de nosotros es, ante todo, un ciudadano de un determinado Estado europeo. Es en él donde obtiene su documento de identidad, donde vota, donde sus derechos políticos y sociales son primeramente tutelados, donde ha sido educado y ha aprendido la lengua que habla, etc. A la inversa, cada uno de nosotros, cuando se encuentra en otro Estado europeo ¿qué es? ¿Podemos decir verdaderamente que es un ciudadano europeo? Podemos decirlo, así lo hacíamos en $1993^{4}$, pero a cambio de volver fluida la calificación de ciudadano. Puesto que, a fin de cuentas, cada uno de nosotros, cuando permanece en otro país europeo, es un huésped más que un ciudadano. Es lo que podríamos definir técnicamente como un huésped euro-

\footnotetext{
${ }^{4}$ Tratado de Maastricht, art. 8: "Citizenship of the Union is hereby established. Every person holding the nationality of a Member State shall be a citizen of the Union".
} 
peo. A ninguno de nosotros nos es ofrecida soberanía alguna en los otros Estados en que nos encontramos. Se nos ofrece hospitalidad. Y esta amplia hospitalidad que nos corresponde debe haber sido acordada y regulada en todo detalle por pactos internacionales específicos vinculados a los tratados europeos. Esto es, por el momento, la Europa política.

La Europa de hoy es, en tal sentido, un espacio de hospitalidad política - no de hospitalidad ética o religiosa, fundada sobre usos y costumbres como en la antigüedad. El efecto hospitalidad es el mayor efecto político del proceso de unificación económica del espacio europeo ${ }^{5}$. Pero preguntémonos ahora: ¿Sobre qué está basada esta hospitalidad política, que es la genuina invención de la Europa posbélica? La respuesta es tan simple como dura para algunos: está basada en el respeto de la soberanía popular heterogénea, capaz de convivir en el mismo espacio político de hospitalidad que es el espacio europeo. Si estas soberanías nacionales viniesen a menos también Europa vendría a menos como espacio de hospitalidad. Se iría hacia un super-Estado federal europeo, con ciudadanos europeos y soberanía efectiva de un pueblo europeo. Pero mientras este pueblo no exista, y por ahora no hay de él ni la sombra, la única posibilidad de una Europa política es la Europa de la hospitalidad. Lo que significa una Europa de las naciones.

¿Es una mala noticia? Sí y no, según el punto de vista. Sí, si, por las razones más diversas, concebimos la Europa política exclusivamente en términos de Europa soberana. No lo es. O lo es bastante menos, si enfocamos la Europa política en los únicos términos en que esta Europa parece poder existir hoy: la Europa de la hospitalidad. A pesar de las apariencias, no es esta Europa política -espacio de hospitalidad codificada y aun codificable- la que va a desencadenar identidades resurgidas y reacciones nacionalistas exasperadas, porque esta Europa política se basa precisamente en el respeto de las identidades nacionales de los distintos pueblos europeos, que no pone en cuestión sino que en todo caso exalta como fuente de democracia. Las grandes democracias europeas, hasta hoy, no son Estados distintos: son democracias nacionales ${ }^{6}$. Y solo cuando es cuestionada o disminuida o puesta en duda la soberanía popular de las naciones europeas, entonces tienden a producirse en Europa imprevistas reapariciones identitarias y paroxísticas tensiones nacionalistas. Esto es cuanto se ha verificado con terrible puntualidad en los últimos veinte años ${ }^{7}$, y más en general en el siglo transcurrido. Esto es cuanto aun sucederá si no se cambia la ruta en el proceso de integración política. Hospitalidad y soberanía devienen, a la

\footnotetext{
${ }^{5}$ Directiva 2004/38/CE.

${ }^{6}$ P. Manent, La raison des nations. Reflexions sur la démocratie en Europe, Paris, Gallimard, 2006; D. Miller, On Nationality, Oxford, Oxford University Press, 1995.

${ }^{7}$ H. Kriesi, E. Grande, R. Lachat, M. Dolezai, S. Bornschier, T. Frey, "Globalization and the transformation of the national political space: Six European countries compared", en European Journal of Political Research 45, 2006, pp. 921-956.
} 
luz de las precedentes consideraciones, los nombres de dos diferentes pertenencias políticas, la pertenencia nacional y la pertenencia europea, que se distribuyen sobre dos diferentes espacios políticos y que circunscriben dos diferentes comunidades políticas: de una parte tenemos los pueblos soberanos, los pueblos-nación, compuestos de ciudadanos que pertenecen a los Estados miembros; por otra, tenemos una única, inclusiva comunidad de huéspedes, compuesta por individuos que pertenecen a la Unión europea.

Esta comunidad vota a los representantes propios en las instituciones europeas, que pueden dictar una serie de medidas cuya legitimidad está regular y puntualmente garantizada por los Estados soberanos. Una tal legitimidad, distinta de la soberanía estatal que constituye su fuente, es sancionada de hecho, bien con tratados adecuados, o bien con adaptaciones legislativas efectuadas por los parlamentos nacionales o medidas análogas adoptadas por los órganos de los Estados soberanos. Así tiende a funcionar tanto el derecho comunitario originario, hecho sobre todo de tratados internacionales, como el derecho comunitario derivado, con su ingenioso vocabulario hecho de reglamentos, directivas, decisiones, dictámenes y recomendaciones. También en el caso de los reglamentos, que son similares a una ley de nivel comunitario, los Estados entran siempre en tratos entre sí, a veces con acaloradas negociaciones, de los contenidos de las diversas medidas. En este cuadro normativo, la soberanía nacional de los Estados miembros y la legitimidad supranacional de la Unión Europea resultan, pues, planos no confundibles. Convendría volver menos opaco el reparto básico de las funciones y de los papeles, sobre todo en el instante en que perdiese credibilidad el diseño de una veloz disolución de la soberanía nacional en una soberanía federal etiquetada $\mathrm{UE}^{8}$.

La cuestión que sigue es: ¿quién puede o quien debe formar parte de esta comunidad europea de huéspedes? ¿Deberían formar parte de ella solamente los ciudadanos de los Estados europeos? No necesariamente. Podrían formar parte también, de buen grado, ciudadanos provenientes de otros países, a los que fuera reconocido el estatuto de huéspedes europeos. Para conseguir tal objetivo, convendría que las políticas administrativas de los flujos migratorios fueran centralizadas a nivel comunitario con actos adecuados de legitimación de los órganos de la UE por parte de los Estados soberanos. Esto permitiría alcanzar rápidamente dos resultados. En primer lugar, permitiría trazar una única frontera para toda la Europa política, que posibilitaría por vez primera hablar en sentido propio de una sola Europa política. En segundo lugar, permitiría distinguir de manera neta e inequívoca el dominio de las soberanías nacio-

\footnotetext{
${ }^{8}$ Lo que llamamos aquí principio de legitimidad no es otro, en última instancia, que una redefinición unitaria de los dos principios de subsidiariedad y de proporcionalidad que están ya en la base del Tratado de Lisboa (art. 5). Como recientemente ha observado una eminente constitucionalista alemana: "Quien quiera ganarse a los ciudadanos para la Unión Europea deberá ante todo tomar en serio el principio de subsidiariedad" (J. Limbach, "Es gibt keine europäische Identität", en Frankfurter Allgemeine Zeitung, 28 agosto 2012).
} 
nales del dominio de la soberanía europea. Este segundo dominio estaría de hecho poblado por ciudadanos europeos y ciudadanos no europeos agrupados todos por el estatuto político de huéspedes europeos, libres de circular por el mismo espacio de civilidad y dotados sin excepción del derecho de elegir a los propios representantes en las instituciones europeas. La expedición de ciudadanía en este o aquel Estado europeo continuaría sin restar prerrogativas a los Estados particulares.

Operando así, el espacio político europeo no coincidiría ya con un espacio multinacional, mera sumatoria de las identidades nacionales de los pueblos particulares europeos, sino que coincidiría en todo caso con un espacio de hospitalidad dirigido por adecuadas reglas y orientado a la definición y progresiva subjetivación histórica de una inédita comunidad política que podríamos definir en cierto modo como un pueblo de huéspedes, o un pueblo de extranjeros, irreductible a una simple reunión multinacional o multicultural. La gramática política de la hospitalidad podría tender, de este modo, a una lenta subjetivación no identitaria del espacio político europeo, que por un lado pondría a recaudo las identidades nacionales y su patrimonio de democracia y civilidad, y por otro exaltaría no tanto la hibridación cultural cuanto la convivencia pacífica entre personas con historia y proveniencia tan diferente como para encontrar, más de lo que se cree, oscura e inaceptable la hipótesis de una hibridación cultural. Y esto por ambos lados. Cerrar la puerta de los Estados-nación y abrir la puerta de la Europa política: probablemente no se puede hacer una cosa sin la otra. La alternativa sería cerrar y abrir ambas puertas, con efectos nefastos en los dos casos. Cerrar ambas puertas significaría provocar el asedio del continente europeo por una masa de esclavos, con efectos de deterioro y embrutecimiento de la convivencia social que ya ahora se pueden constatar en muchos lugares. Abrir ambas puertas significaría exponer Europa al riesgo de una rápida depauperación de su patrimonio original de civilidad y cultura política, con efectos inmediatos de refuerzo identitario y trágica recrudescencia nacionalista.

La completa (re)codificación jurídico-política de la UE como Europa de la hospitalidad exigiría dar forma acabada a cuanto ya existe, de hecho, en esbozo. Sin embargo, este paso del de facto al de iure no podría y no debería realizarse solo, o bajo solicitación exclusiva de una reducida élite política. Para tener un auténtico sentido político y recibir el justo impulso propulsor, debería ser precedida de un acto democrático de alcance europeo. Este acto no debiera ser entendido como un acto constituyente, de nuevo orientado hacia la Constitución de una Europa soberana. Este acto debiera más bien ser entendido como un acto declarativo, sometido en el mismo día a escrutinio de referendo en todo el continente europeo. Los pueblos-nación de toda Europa deberían expresarse ese día sobre un documento fundador de la Europa de la hospitalidad que tuviera el mismo valor que en los siglos pasados han tenido documentos como la Declaración de independencia de los Estados Unidos de América o la Declaración de los derechos del hombre y del ciudadano de la Francia revolucionaria. En el pasado, ninguno de estos documentos, o de otros similares que se podrían citar, 
cumplió en sí y por sí el papel de acto constituyente. Pero todos estos documentos asumieron el papel de actos declarativos con los que determinados pueblos o comunidades anunciaron al mundo su propia existencia, antes incluso de transformarse en efectivos poderes constituyentes. Estos actos declarativos han de ser considerados en tal sentido como actos preliminares a los actos constituyentes, los cuales están destinados a seguirlos después de un lapso de tiempo variable, de pocos días a muchos años, según las circunstancias históricas y las variables políticas en juego.

El acto declarativo fundamento de la Europa de la hospitalidad podría ser, por ejemplo, una Declaración de la dignidad del huésped europeo, una declaración similar podría incluir el texto de la Carta de los derechos fundamentales de la Unión Europea, pero debiera ser precedida de un preámbulo que codificase la figura del huésped europeo en la que todos los ciudadanos de los Estados miembros fueran invitados a reconocerse; así como debiera detallar una lista de reglas, los deberes del huésped europeo, sobre la que todos los ciudadanos de los Estados miembros serían llamados a fijar de una vez para siempre los límites simbólicos, morales, políticos de la nueva Unión Europea. Este es el documento al que podrían jurar en seguida fidelidad todos los que, sin pertenecer a un Estado europeo, quisieran adquirir el estatuto de huésped europeo.

En el centro de este acto declarativo debieran figurar principios idóneos que reiterasen la peculiaridad de la civilidad jurídico-política europea. A tal fin, el ya consolidado principio de la dignidad humana, extraño a toda otra civilidad jurídico-política, comprendida la americana, podría servir de pivote de toda la Declaración. Pero entretanto sería crucial la inclusión de un principio jurídico-político de hospitalidad capaz de convivir con los principios de ciudadanía ya vigentes en los Estados europeos. En tal sentido, si la ciudadanía en los Estados está regulada por el principio del ius soli y del ius sanguinis, la hospitalidad en Europa podría ser regulada por el de ius laboris. El derecho a la hospitalidad para los ciudadanos no europeos sería así vinculado al desarrollo de la actividad laboral debidamente documentada y al tiempo tutelada jurídicamente ${ }^{9}$.

Una sola vez, en la historia pasada, se ha visto algo de este género. El artículo 20 de la Constitución de la República Socialista Federativa Soviética Rusa de 1917 rezaba así: "En virtud de la solidaridad de los trabajadores de todas las naciones, la República Socialista Federativa Soviética Rusa concede todos los derechos políticos de los ciudadanos rusos a los extranjeros que residan en el territorio de la República por razones de trabajo". Hans Kelsen, no un bolchevique pero sí el más equilibrado e influyente jurista del siglo xx, comentaba así esta innovación: "La experiencia de la reciente evolución constitucional enseña que los derechos políticos no deben ser de hecho ligados a la nacionalidad. La Constitución de la Rusia Soviética ha abandonado, por ejemplo, una barrera secular y garantiza la plena igualdad de derechos

\footnotetext{
${ }^{9}$ D. Tarizzo, "Un popolo di stranieri. Sull diritto all'ospitalità iure laboris", en A. Trucchio (ed.), Cartografie di guerra. Le ragioni della convivenza a partire da Kant, Milano, Mimesis, 2011.
} 
políticos también a todos los extranjeros que se encuentran en Rusia por finalidades de trabajo. En el característico desarrollo jurídico cuya lenta evolución recoge la idea de humanidad, por la que el ciudadano extranjero, otrora considerado como un "fuera de la ley", acaba por adquirir gradualmente la igualdad de los derechos civiles, aunque hoy en casi todo el mundo no pueda aun gozar de los políticos, el paso dado por la Unión Soviética representa un hecho de importancia histórica"10.

La asignación a la UE de las competencias relativas a la regulación de los flujos migratorios y a la gestión de la inmigración comportaría -además de la creación inmediata de una oficina especial- una sustitución de las normativas nacionales sobre el derecho de residencia y sobre las cartas de residencia por una normativa única europea sobre el derecho de hospitalidad y sobre las cartas de hospitalidad. Esto estaría perfectamente en línea con las recientes orientaciones expresas de la UE en materia de "permiso único" y de emparejamiento tendencial de los derechos de los trabajadores comunitarios y extracomunitarios ${ }^{11}$.

La ulterior ampliación de los derechos de los trabajadores provenientes de terceros países y el injerto de estos derechos en una renovada arquitectura normativa e institucional de la UE tendría evidentes efectos civilizatorios. Si a esto se añadiese el goce de derechos políticos en el espacio europeo, en términos de electorado activo y pasivo, se intuye qué potencialidad emancipatoria podría emanar, con el tiempo, de la figura del huésped europeo. Además de homologar parcialmente la condición de los ciudadanos comunitarios y de los extra-comunitarios en el espacio político europeo, sin por ello pretender homologar forzosamente las identidades históricas y culturales de unos y otros en un mismo espacio de ciudadanía nacional, la figura del huésped europeo permitiría sentar inmediatamente las bases de una auténtica vida democrática en un espacio europeo políticamente integrado. Una vez que la UE estuviera legitimada para fijar y tutelar a nivel comunitario los derechos de los trabajadores, estimulando así al mismo tiempo una progresiva uniformización del mercado laboral en el interior del continente, es presumible que las diversas formaciones sindicales distribuidas sobre el territorio nacional hicieran converger sus luchas en el interior de movimientos transnacionales o dentro de esquemas de alianza sindical que tenderían a sobrepasar los confines y los intereses de los respectivos países de pertenencia. Al nacimiento de los movimientos sindicales de vocación transnacional le seguiría, con toda probabilidad, una contraposición política entre una Izquierda y una Derecha europeas acerca de temáticas respecto del trabajo y su tutela en el interior del espacio europeo. Y esto a su vez permitiría encender gradualmente la confrontación democrática, no solo entre los partidos políticos nacionales, sino también entre partidos políticos europeos.

\footnotetext{
${ }^{10}$ H. Kelsen, "Vom Wesen und der Demokratie", trad. it. "Essenza e valore della democracia", en $\mathrm{La}$ democrazia, Bologna, Il Mulino, 1995, p. 61.

${ }^{11}$ Directiva 2011/98/UE.
} 
No hay que contar con que este éxito histórico-político de la Europa de la hospitalidad hubiera de ser hostigado a ultranza por las Derechas nacionalistas. La ventaja que estas últimas obtendrían es el pleno reconocimiento de las soberanías nacionales, unido a una rígida distinción entre la legitimidad de las instituciones europeas y la soberanía de los Estados miembros. A los ojos de todos, el respeto de las soberanías estatales sería acompañado por el respeto de las identidades históricas y culturales de las diversas naciones europeas, cuyo espacio de ciudadanía no vería afectado apenas por la aparición del huésped europeo.

También sobre el plano de la dialéctica entre parlamentos nacionales y parlamento europeo, la perspectiva de una Europa de la hospitalidad podría ofrecer garantías de equilibrio y compensación entre instancias políticas de orientación opuesta. De un lado, el derecho de voto al parlamento europeo daría a todos los huéspedes europeos, incluidos los ciudadanos extra-comunitarios dotados de una carta de hospitalidad, la facultad de orientar las políticas europeas en materia, por ejemplo, de reglamentación del trabajo. Del otro, la legitimidad de tales medidas quedaría anclada en la soberanía última de los parlamentos nacionales, con electorados más restringidos, siempre libres de secundar o corregir las orientaciones políticas expresadas a nivel europeo. Esta doble dimensión política, hecha de legitimidad de los órganos europeos y soberanía de los órganos nacionales, podría así iniciar un proceso de débil emancipación política de aquellos que algunos filósofos han bautizado como "la parte de los sin parte"12, produciendo una sustancial "equivalencia"13 con los ciudadanos de los Estados miembros en el espacio político europeo. Al mismo tiempo, la naturaleza negociativa y los vínculos procedimentales de la actividad normativa en sede europea mantendrían bajo el nivel de impacto de la fracción del electorado europeo compuesta de ciudadanos extra-comunitarios, permitiéndoles dar expresión democrática a su propia presencia sobre el continente sin desencadenar excesivas reacciones xenófobas de los ciudadanos de los Estados miembros.

En esta perspectiva, las tensiones y bloqueos que se pudieran producir entre los órganos legítimos de la UE y órganos soberanos de los estados miembros, o entre el parlamento europeo y los parlamentos nacionales, no serían concebidos como factores meramente negativos. Podrían jugar un papel positivo, alimentando debates públicos y democráticos sobre las competencias efectivas de las instituciones europeas y el contenido de sus iniciativas. Como se ha podido constatar durante la crisis de la deuda, es propiamente sobre el fondo de la crisis sistémica de las estructuras institucionales que se acrecienta la demanda de democracia en la población, con salidas políticas que por definición no son programables. Estos casos, de tensiones y bloqueos entre órganos legítimos de la UE y órganos soberanos de los Estados miembros, o entre el parlamento europeo (con electorado ampliado) y los parlamen-

\footnotetext{
12 J. Ranciere, La Mésentente, Politique et philosophie, Paris, Galilée, 1995.

${ }^{13}$ C. Mouffe-E. Laclau, Hegemony and Socialist Strategy, London, Verso, 1985.
} 
tos nacionales (con electorado restringido), podrían ser vistos como crisis sistémicas semi-institucionalizadas, cuyo efecto colateral sería la constante sensibilización democrática de todo los que habitan en el espacio político europeo.

En fin, siempre desde esta perspectiva y siempre a la luz de una brecha fundamental entre el espacio político europeo y los espacios políticos nacionales, la Europa de la hospitalidad - como débil entidad política, privada de una común raíz identitaria- no podría sino estar abierta a la inclusión de todo Estado-nación que lo demandase, con la condición de que en tal Estado se respetasen los principios jurídicos y democráticos que ya delimitan, y deben seguir delimitándolo, el espacio político europeo. El mantenimiento de un mercado común europeo, si bien remodelado y reconfigurado en vista de un mayor equilibrio entre las economías de los Estados miembros, podría continuar funcionando como fuerte incentivo a la integración de las regiones de alrededor.

La Europa del euro, por como se ha configurado hasta aquí, no es compatible con el proyecto de una Europa de la hospitalidad. La Europa de la hospitalidad es entendida como un proyecto alternativo al de una integral unificación económica de la eurozona. Una tal unificación económica entre los Estados europeos, llevada a sus extremas y lógicas consecuencias, debiera servir a los fines de un reparto de las deudas públicas, acompañada de una unión fiscal. En tal caso, nos encontraríamos frente a una acabada soberanización de la UE. Soberano, en efecto, no es tanto o solamente quien decide sobre el estado de excepción como reza un engañoso mantra de la teoría política del xx, cuanto quien tiene el poder de recaudar y administrar el dinero público. Es así como los Estados modernos han afirmado desde sus orígenes la propia soberanía. Si la Unión Europea asumiera un papel análogo, si, por ejemplo, sus directivas deviniesen vinculadas al gasto público de los Estados particulares, la soberanía nacional cedería de hecho el paso a la soberanía federal de la UE. Los dos espacios políticos, el nacional y el europeo, tenderían así a confluir uno en el otro, dando vida a un super-Estado europeo. Llamar de otro modo a esta nueva entidad soberana, por no herir la sensibilidad de las naciones europeas, no cambiaría su naturaleza. La historia, a través de la presión de los mercados financieros, va a emitir una sentencia definitiva sobre la posibilidad concreta de realizar un diseño de ese género en breve período. $\mathrm{Si}$, como parece más bien probable, prescindiendo de la voluntad de los gobiernos particulares y de las instituciones europeas, una rápida soberanización de la UE no tendrá éxito, la Europa de la hospitalidad será una de las alternativas posibles. En este caso, retornando a formas más flexibles y coyunturales de unión económica, sería esencial, no obstante, salvaguardar y relanzar la idea de una Europa política, imprimiendo al mismo tiempo un giro radical a los procesos de asimilación política de los emigrantes extra-europeos que en los años venideros continuarán haciendo ruta hacia el continente.

Este no sería, por otra parte, el único sentido de la Europa de la hospitalidad. Los Estados Unidos de Europa podrían continuar siendo el objetivo a largo plazo de una débil Europa política. La recalificación del "pueblo europeo" como pueblo de hués- 
pedes, o pueblo de extranjeros, podría también ser vista como el primer paso hacia un más gradual y realista proceso de sedimentación histórica de un pueblo homogéneo y potencialmente soberano. La Europa de la hospitalidad podría ser entendida, por tanto, como el marco de una larga transición histórica hacia un resultado aún más ambicioso por ahora impracticable.

En el trayecto que nos separa de una Europa soberana, la categoría de ciudadanía europea resulta siempre confusa y deletérea. Resulta confusa porque no fotografía con exactitud la realidad histórico política en la que nos movemos por el momento en el continente, codificable bastante mejor en términos de hospitalidad europea. Resulta deletérea porque, no siendo distinguible de la categoría de soberanía nacional, alimenta dudas y sospechas en los pueblos nación europeos que en varias ocasiones han rechazado el diseño de una repentina soberanización de la UE y sin embargo ven repetirse, de palabra si no más, el modelo de una gran nación europea.

Si pensamos en el estrecho ligamen histórico entre ciudadanía y nacionalidad en países como Francia o Alemania, no puede dejar de saltar de inmediato a los ojos la profunda discrepancia entre la ciudadanía nacional y la llamada ciudadanía europea. La idea de ciudadanía de los Estados soberanos va conexa siempre con la idea de pertenencia a un cuerpo colectivo, el cuerpo de la nación compuesto por todos los ciudadanos que son súbditos y soberanos, sujetos y objetos del mismo poder legislativo en el mismo territorio. Poco importa, a fin de cuentas, que la ciudadanía sea regulada por el ius sanguinis, en el que la idea de pertenencia a un cuerpo colectivo es parcialmente naturalizada, o por el ius soli, en el que la idea de pertenencia a un cuerpo colectivo es completamente juridificada. Queda el hecho de que en los Estados soberanos la ciudadanía, regulada bien de un modo bien del otro, indica la perfecta identidad y coextensividad de la pertenencia a un mismo espacio colectivo y de pertenencia a un mismo cuerpo colectivo - el cuerpo del pueblo soberano. No hay intervalo aquí entre cuerpo y espacio. Y es precisamente sobre la ausencia de intervalo entre cuerpo colectivo y espacio colectivo que se basa el concepto netamente moderno de soberanía popular. Del todo diverso, por el contrario, es el caso del espacio político europeo, por como se ha ido configurando en los últimos treinta años.

En este caso, en efecto, aunque se puede hablar de espacio colectivo (político) y de pertenencia colectiva (política), no se puede hablar de cuerpo colectivo (político), ya que no existe por ahora un pueblo europeo dotado de soberanía o dotado de suficiente homogeneidad para aspirar, al menos, a la autodeterminación política. Sabemos que este pasaje, precisamente, de la soberanía de los pueblos-nación europeos a un único pueblo europeo, entendido como una gran nación europea, es lo que continúa siendo problema. La pertenencia a Europa no indica por tanto, al menos por ahora, la pertenencia a un cuerpo colectivo, sino la pertenencia a un espacio colectivo que no coincide con un cuerpo colectivo. Por eso, a diferencia de la categoría de ciudadanía europea, la categoría de hospitalidad europea no se sobrepone de manera incómoda y virtualmente insidiosa al principio de la ciudadanía nacional. Por eso, 
pues, la gramática de la hospitalidad europea debiera sustituir a la gramática de la ciudadanía europea, si el proyecto de una inmediata soberanización de la UE se va a pique definitivamente. La hospitalidad política es aquella forma inédita de pertenencia colectiva, diversa de la soberanía, que ha sido inventada en Europa en los últimos treinta años, de lo que conviene tomar nota ${ }^{14}$.

La actual crisis de la deuda en Europa es debida a varios factores. Ya en diciembre de 2011, en una llamada para una salida concertada del euro firmada por 12 economistas y publicada en Le Monde, dos de las causas principales habían sido localizadas con suficiente nitidez: 1) el crecimiento inexorable de la deuda externa en los países débiles de la eurozona; 2) los desequilibrios económicos de escala global producidos por la desregulación financiera y en particular, por la abolición del Glass-Steagall Act en $1999^{15}$. Otras concausas se podrían enumerar, pero no cambiaría la sustancia del problema con el que Europa tiene que confrontarse hoy, que es una sustancia política más que económica.

Para volver efectiva una salida de la crisis como la sugerida por estos tiempos de tecnócratas europeos no hay duda de que debiéramos confiar en un factor no económico, denominado mayor "solidaridad" entre los Estados europeos. Solo sobre esta base podría lograrse compartir las deudas públicas y avanzar rápidamente en dirección de una soberanización de la UE. Sin embargo, esta solidaridad mayor entre los

\footnotetext{
${ }^{14}$ La actual categoría de ciudadano europeo presenta algún parecido con la categoría de ciudadano de la Commonwealth de las Naciones, tal como se encuentra establecida en el derecho británico. En ambos casos, ser ciudadano de un determinado Estado garantiza la tutela de ciertos derechos no solo por parte del propio Estado sino de parte igualmente de los otros Estados miembros de la unión (Europa) o del organismo intergubernativo (Commonwealth). Según el British Nationality Law, ser ciudadano de la Commonwealth sin gozar de la ciudadanía británica significa, por ejemplo, que se tiene derecho a elegir y ser elegido al parlamento británico, con tal de que se esté provisto de un permiso de residencia en Gran Bretaña (algo similar se podría realizar también en Europa con el paso de la ciudadanía europea a la hospitalidad europea). Este tipo de reglamentación jurídica es herencia del Imperio británico y muestra como la pertenencia a un cuerpo colectivo puede a veces soportar las trazas de desequilibrios y asimetrías que en el pasado han estriado este o aquel cuerpo político. En este caso, la figura del ciudadano de la Commonwealth es una de las sub-entradas a la figura del mero "súbdito británico", que tiempo atrás podía indicar una persona nacida en suelo británico pero desprovista de ciudadanía (los habitantes indígenas de las tierras colonizadas). Con el desmembramiento del Imperio y la gradual emancipación de las colonias, la adquisición de una ciudadanía no británica por parte de los ex-súbditos de las colonias ha sido combinada con un lazo de pertenencia al Reino Unido de los habitantes de las viejas posesiones coloniales. De tales complicadas estrías y cicatrices históricas no hay traza, naturalmente, en el espacio político europeo, que siendo desde el origen un espacio privado de cuerpo colectivo, podría devenir en el futuro la matriz de una absoluta novedad histórica, la matriz de un pueblo soberano que, sedimentándose lentamente en este espacio político sin cuerpo, esté finalmente en condiciones de evitar la gramática política de la nacionalidad.

${ }^{15}$ G. Colletis, A. Cotta, J.-P. Gérard, J.-L. Gréau, R. Hureaux, G. Lafay, P. Murer, L. Pinsolle, C. Rochet, J. Sapir, P. Villin, J.-C. Werrebrouck, "Pour un démontage concerté de l'euro", en Le Monde, 23 diciembre 2011. En Italia, la investigación más exhaustiva sobre la crisis de la eurozona ha sido realizada por A. Bagnai, Il tramonto dell'euro, Regio Emilia, Imprimatur, 2012.
} 
pueblos europeos, más que entre los gobiernos europeos, no ha aparecido en el horizonte. Y este es un dato histórico-político que el análisis económico no ha recogido ${ }^{16}$. La Europa del euro, desde el inicio, no ha sido concebida como una entidad política fundada sobre la solidaridad entre los pueblos sino como una entidad económica fundada sobre la competitividad entre capitales. En este escollo Europa está destinada ahora a encallar. Que en un marco tal la lógica de los intereses nacionales estuviera destinada a prevalecer sobre la lógica de la integración era algo previsible. Así como es previsible que las medidas de austeridad impuestas por los países fuertes a los países débiles de la eurozona desencadenarán insostenibles tensiones políticas y sociales. También es previsible, a la vez, que en virtud de tales tensiones la moneda única, antes o después, explotará. Nada parece que pueda frenar esta deriva.

Todo lo que se puede hacer, en cualquier caso, es comenzar a proyectar el después. La progresiva clausura de las naciones europeas en sí mismas, a la que la lógica histórica en marcha conduce fatalmente, podría y debería ser compensada por una lógica política de distinto signo que, a pesar de la parcial impotencia frente a los automatismos que se están desplegando, mantenga abierto lo más posible el espacio europeo como espacio de paz, civilidad y hospitalidad. Por eso una Europa política alternativa a la Europa del euro ha de imaginarse desde ahora, a pesar del hundimiento, quien sabe por cuánto tiempo, de la idea misma de una Europa política. Por eso, ha de tenerse sin demora una discusión pública sobre los escenarios posibles y delinearse el perfil de las medidas que puedan fijar, cuando llegue el momento, algunas de las conquistas de los últimos cincuenta años en un sólido y renovado marco institucional. Por eso ha de estudiarse de inmediato el modo de ofrecer a los pueblos europeos la facultad de elegir democráticamente en qué Europa quieren habitar en los próximos años. No hacerlo significaría rendirse pasivamente a la corriente de los eventos sin siquiera intentar guiarlos.

Si el proyecto de una débil Europa política no es compatible con el proyecto de una plena unificación económica de la eurozona en un breve periodo, no es compatible tampoco con una completa deflagración del mercado común y con la extinción del principio de la libre circulación de las personas. Activar una lógica política de gobierno de la crisis significa, en esta óptica, trabajar también en vista de una diversa configuración del espacio económico europeo, concebido como un espacio relativamente homogéneo e integrado de cambio. Significa preparar una salida de la unión monetaria que esté en condiciones de poner freno al mercantilismo cada vez

\footnotetext{
${ }^{16}$ Dicho en honor a la verdad, la falta de "solidaridad" del contribuyente alemán no se puede llevar, sobre todo hoy, al banco de los acusados, solo se trata de un torcido e irreflexivo egoísmo nacional. Esta reacción es de hecho alimentada también por una viva y justificada preocupación de los ciudadanos alemanes por la suerte de la democracia en Europa. Es sobre esto que, más allá de las caricaturas ofrecidas por muchos medios de información, trata el debate público alemán. ¿Quién decide a nivel europeo? ¿Qué garantiza la democracia en las decisiones sustraídas a los gobiernos nacionales? Como es notorio, en el actual marco institucional de la UE no existen respuestas tranquilizantes a tales cuestiones.
} 
más intrusivo en Europa y poner freno, simultáneamente, a la desregulada movilidad de capitales que ha sido uno de los factores determinantes de los actuales desequilibrios ${ }^{17}$. Todo esto implica, sin duda, una compleja negociación entre los Estados europeos. Pero de nuevo, si esta negociación reflejara solo los intereses particulares de las diversas naciones sin estar inspirada por una nueva idea de la Europa política capaz de encauzar el proceso histórico en curso y convertirlo en un potencial progreso, Europa volvería a fragmentarse en pequeñas patrias sin ligamen alguno entre sí y sin ninguna esperanza de lograr acuerdos concretos. En ausencia de un horizonte político que alinee las naciones europeas sobre un mismo frente de civilidad y de vocación para el desarrollo no será posible salvar nada ni siquiera la integración económica hasta aquí conseguida ni sus efectos más beneficiosos. La historia no sigue un camino recto. Si la previsible caída de la moneda única no es gobernada en la búsqueda de nuevas coordenadas de avance en el proyecto europeo, Europa no regresará a un estadio anterior sino que desaparecerá, como realidad y como promesa, por larguísimo tiempo ${ }^{18}$.

Estamos entrando en una fase histórica que algunos filósofos definirían como "rara", aquella en la que se abren ventanas de oportunidad para actos políticos de extraordinario alcance. No se puede prever cuánto tiempo durará esta fase. Lo que puede decirse con seguridad es que asigna a los actores políticos una responsabilidad también "rara", de lo que darán cuenta ante el tribunal de la historia. En una coyuntura así hay que ser conscientes de que no se puede no actuar políticamente. También la inacción política, o la delegación de decisiones en sedicentes tecnócratas, es una conducta política que como tal será sancionada por los historiadores del futuro. Dicho esto, la tan invocada solidaridad entre los pueblos europeos en la que muchos ven la única vía de salida de la crisis política en curso, no es cosa que los gobiernos europeos puedan crear de la nada. Por el momento la voluntad de los pueblos europeos no va en esta dirección, como se ha podido constatar en varias ocasiones en

\footnotetext{
${ }^{17}$ Véanse las proféticas advertencias lanzadas hace quince años por P. De Grauwe, "The Euro and Financial Crises", en Financial Times, 20 febrero 1998. Ver también las observaciones sobre la economía globalizada desarrolladas por R. Mangabeira Unger, Free Trade Reimagined. The World Division of Labor and the Method of Economics, Princeton, Princeton University Press, 2007: "In the long run, the cause of free flows of capital may be better served than harmed by a regime that avoids requiring those who would advance that cause to wear a straitjacket of conformity. The place accorded in established dogma to sympathy for the movement of capital should be given instead to the movement of people. [...] The movement of people and ideas is, however, more than useful; it is sacrosanct" (pp. 194 y 209).

${ }^{18}$ Sobre los escenarios y la modalidad de salida del euro desde un punto de vista técnico-económico se pueden consultar on line los estudios de R. Bootle (Leaving the Euro: A Practical Guide) y J. Sapir ( $S$ 'Il faut sortir de l'Euro). Hay que señalar también un artículo de B. Frey sobre los posibles escenarios económico-políticos de después del euro ("Was kommt nach Euro und EU", en Frankfurter Allgemeine Zeitung, 29 agosto 2011) y una contribución de C. B. Blankart sobre las causas económicas y las posibles soluciones de la crisis europea ("Die Euro-Zauberlehrlinge", en Frankfurter Allgemeine Zeitung, 13 agosto 2012).
} 
los últimos años, meses, días. La solidaridad, no entre los gobiernos sino entre los pueblos europeos, si se da algún día, será el fruto de un lento proceso histórico, canalizado por justas vías. En una perspectiva de este tipo, obstinarse en excluir que haya vías alternativas a la Europa del euro no parece un signo de precaución y realismo. En el punto en el que estamos, parece un signo de analfabetismo político, sazonado de una buena dosis de analfabetismo democrático. Como enseña la historia moderna, el éxito fatal de una tal conducta política será, si no una "apelación al cielo" por parte de los pueblos, cuando menos un terremoto violento. Algo que muy a menudo en el pasado las clases políticas no han sentido llegar. 